\title{
LERR ILLUMINATIONS ou a comunicação adiada
}

Os poemas mais conhecidos de Rimbaud são aqueles que ele escreveu entre quatorze e dezesseis anos. São poemas de revolta contra a vida provinciana, a família, a ordem social e contra Deus. São também os poemas que sonham com evasão, como Le Batean ivre.

O episódio mais conhecido da vida de Rimbaud é sua aventura com Verlaine, o tiro de pistola de Bruxelas a que se seguirá a confissão, em grande parte autobiográfica, de Une saison en enfer.

Em contrapartida, os leitores e os especialistas de Rimbaud desconfiam de Illuminations, este conjunto de textos em prosa, muitos dos quais parecem difíceis, até mesmo incompreensíveis. O crítico Todorov falou da "ilegibilidade" das Illuminations. É esta "ilegibilidade" que merece ser questionada e, se possível, esclarecida.

O que se deve primeiramente constatar é que Rimbaud não se preocupou em publicar estes textos. Por quê? Porque ele tem consciência de estar avançado com relação ao leitor de seu tempo.

O leitor do final do século XIX é alguém que espera de um poema, primeiramente, que ele seja escrito em verso (forma tranqüilizadora); em segundo lugar, que ele passe uma mensagem ou uma emoção (como em Victor Hugo ou entre os românticos) e finalmente que ele tenha um referente identificável. 
Ora, o que acontece desde Baudelaire é que a poesia se desvencilhou do alexandrino a fim de se orientar para a prosa, ela não transmite mais um saber nem uma mensagem e perdeu sua força referencial.

Rimbaud é a encarnação dessa postura em seus dois poemas de "Illuminations", "Parade" e "H".

Em francês, "Parade" tem duas significações. É uma parada militar, um desfile de soldados na cidade, por ocasião de uma festa. Significa ainda uma exibição em feira, um espetáculo de rua. O poema de Rimbaud comporta três parágrafos. O primeiro parece descrever um desfile militar, o segundo uma exibição em feira com palhaços e animais. Mas, a surpresa vem com o terceiro parágrafo, em que o autor afirma que apenas ele tem "a chave dessa parada selvagem". Rimbaud, aqui, torna-se um verdadeiro provocador. Ele tem a chave, isto é, o sentido desta parada, que qualifica de selvagem. Coloca, portanto, o leitor em um estado de frustração. O sentido de seu poema, Rimbaud o guarda só para si, excluindo dele o leitor. Isso deve justamente incitar o leitor a forjar uma cumplicidade muito particular com Rimbaud, a sentir-se como o único capaz de compreender o poeta cujo texto parece uma descrição mas que o autor não consegue, todavia, formatar de maneira plena. O poema não fornece ao leitor um saber; ao contrário, parece dinamitar seus reflexos habituais e colocá-lo diante de um desconhecido. Finalmente, a frustração criada provoca uma imantação paradoxal.

O poema "H" vai mais longe ainda. Seu título já é provocador. Não se sabe se "H" designa a primeira letra de Hortense ou então o haxixe (denominado muitas vezes em francês como H). Especialistas dirão que $\mathrm{H}$ é a primeira letra da palavra "hábito", que é uma maneira de designar o mau hábito dos adolescentes que não é outro senão a masturbação ou o onanismo. Este poema aborda, com efeito, a sexualidade (relação com uma prostituta que se chamaria Hortense? relação homossexual na qual se imiscuem atividade e passividade? masturbação simples com sentimentos ou não de culpabilidade?). Mas o essencial do poema reside em sua frase final: "achem Hortense".

Rimbaud nos pede para responder a uma adivinhação, como se todo poema tivesse forçosamente uma resposta. Ora, dessa resposta, ficaremos frustrados. A Hortense do final do texto é a mesma presente no início do texto ("os gestos atrozes de Hortense")?

Esta Hortense, teria ela existido de verdade? Não se acha nenhum traço de uma Hortense nos arquivos das escolas de Charleville, nem nos registros de polícia que recenseiam os nomes das prostitutas. Cabe plenamente acreditar que esta Hortense 
nada tem de referencial e que se deve achar seu segredo no próprio texto. Especialistas sugeriram que Hortense era o anagrama de "Honte" (título de um importante poema de Rimbaud) e de "Eros". A hipótese é sedutora e revela um Rimbaud que brincaria com as palavras. Mas pode-se também pensar que Rimbaud designa uma tensão diferente das habituais. O poeta nos convida a ficar fora dos hábitos de leitura. O leitor procura um sentido. Rimbaud lhe recusa este sentido. Ele revira literalmente o poema de cabeça para baixo. E não é por nada que ele utiliza o verbo (que inventa) "décorpore". Normalmente, um poema é um corpo legível e visível. Com Rimbaud, o poema faz-se um corpo que escapa e se torna invisível. Todorov tem razão em falar de ilegibilidade na medida em que não se sabe verdadeiramente o que Rimbaud descreve. Estas frases nos deixam na incerteza e o poema parece funcionar no vazio. Não é a plenitude da vida que Rimbaud nos mostra mas o vazio da existência.

A revolução de Rimbaud consiste, pois, não em satisfazer ao leitor, mas em frustrá-lo. Com ele, a poesia não é mais uma recompensa, mas faz-nos tomar consciência de nossas frustrações, especialmente no campo da sexualidade que a moral e a religião sempre tiveram tendência a culpabilizar.

Críticos afirmaram que " $\mathrm{H}$ " é um poema escrito sob a influência do haxixe e que não quer dizer nada. Ao contrário, podemos afirmar que " $H$ " é um poema que dinamita nossos reflexos preguiçosos de leitor e nos incita sempre a recolocar em questão a própria poesia. As falhas de um texto são o perfeito espelho no qual podemos questionar nossa obscuridade fundamental.

As mudanças de hábito de leitura pedem tempo para serem assimiladas - o que explica uma comunicação adiada.

\section{PARADE}

Des drôles très solides. Plusieurs ont exploité vos mondes. Sans besoins, et peu pressés de mettre en oeuvre leurs brillantes facultés et leur expérience de vos consciences. Quels hommes mûrs! Des yeux hébétés à la façon de la nuit d'été, rouges et noirs, tricolores, d'acier piqué d'étoile d'or; des facies déformés, plombés, blêmis, incendiés; des enrouements folâtres! La démarche cruelle des oripeaux! - Il y a quelques jeunes, comment regarderaient-ils Chérubin? - pourvus de voix effrayantes et de quelques ressources dangereuses. On les envoie prendre du dos en ville, affublés d'un luxe dégoûtant. 
Ô le plus violent Paradis de la grimace enragée! Pas de comparaison avec vos Fakirs et les autres bouffonneries scéniques. Dans des costumes improvisés avec le goût du mauvais rêve ils jouent des complaintes, des tragédies de malandrins et de demidieux spirituels comme l'histoire ou les religions ne l'ont jamais été. Chinois, Hottentots, bohémiens, niais, hyènes, Molochs, vieilles démences, démons sinistres, ils mêlent les tours populaires, maternels avec les poses et les tendresses bestiales. Ils interpréteraient des pièces nouvelles et des chansons "bonnes filles". Maîtres jongleurs, ils transforment le lieu et les personnes et usent de la comédie magnétique. Les yeux flambent, le sang chante, les os s'élargissent, les larmes et des filets rouges ruissellent. Leur raillerie ou leur terreur dure une minute, ou des mois entiers.

J'ai seul la clef de cette parade sauvage.

(RIMBAUD. Illuminations. Préface, notices et notes par Jean-Luc Steinmetz. Paris: GF Flammarion, 1989, p. 60.)

\section{PARADA}

Marotos muito sólidos. Vários exploraram vossos mundos. Sem necessidade, e sem pressa de aplicar suas brilhantes faculdades e seus conhecimentos de vossas consciências. Que homens maduros! Seus olhos embotados deverão ser como as noites de verão, negros e vermelhos, de três cores, de aço picotado por estrelas de ouro; fácieis disformes, de estanho, lívidas, incendidas; grosseiras galhofas! O avanço cruel dos ouropéis! - Há alguns jovens - que achariam de Cherubino? - dotados de vozes apavorantes e de alguns apetrechos perigosos. Costumam mandá-los se virar na cidade, pavoneando um luxo degradante.

Ó o Paraíso mais violento da careta enfurecida! Nada de comparações com os vossos Faquires e outras fanfarronadas cênicas. Em trajes improvisados com o gosto dos maus sonhos, encenam farsas, tragédias de malandrins e semideus espirituais como a história e as religiões jamais o foram. Chineses, hotentotes, boêmios, néscios, hienas, Molochs, velhas demências, demônios sinistros, misturam ditos populares, maternais com carícias e poses animalescas. Interpretariam peças atuais e conçonetas "de salão". Mestres jograis, transformam a cena e os personagens, usando truques magnéticos. Os olhos flamejam, o sangue canta, os ossos dilatam-se, escorrem lágrimas e fios vermelhos. Sua troça ou terror não dura mais que um minuto, ou meses inteiros.

Só eu possuo a chave desta parada selvagem.

(RIMBAUD, Arthur. Prosa poética. Edição bilíngüe. Rio de Janeiro: Topbooks, 1998. Tradução de Ivo Barroso, p. 214-215.) 
Toutes les monstruosités violent les gestes atroces d'Hortense. Sa solitude est la mécanique érotique, sa lassitude, la dynamique amoureuse. Sous la surveillance d'une enfance elle a été, à des époques nombreuses, l'ardente hygiène des races. Sa porte est ouverte à la misère. Là, la moralité des êtres actuels se décorpore en sa passion ou en son action - $\hat{O}$ terrible frisson des amours novices sur le sol sanglant et par l'hydrogène clarteux! trouvez Hortense.

(RIMBAUD. Illuminations. Préface, notices et notes par Jean-Luc Steinmetz. Paris: GF Flammarion, 1989,p. 103.)

Todas as monstruosidades violam os gestos atrozes de Hortência. Sua solidão é a mecânica erótica, sua lassidão, a dinâmica amorosa. Sob a vigilância da infância tem sido, em numerosas épocas, a ardente higiene das raças. Sua porta está aberta à miséria. Ali, a moralidade dos seres atuais se descorpora em sua paixão ou em sua ação - Ó frêmito terrível dos amores noviços no solo sangrento e à luz do hidrogênio! encontrai Hortência.

(RIMBAUD, Arthur. Prosa poética. Edição bilíngüe. Rio de Janeiro: Topbooks, 1998. Tradução de Ivo Barroso, p. 292-293.)

\section{SOCR}

\section{Resumo}

Falou-se da "ilegibilidade" das Iluminações e da dificuldade de compreender esses textos. De fato, Arthur Rimbaud, pouco preocupado com o público dos anos 1870, de cujo horizonte de espera ele sabe que seus poemas transbordam amplamente, entrega-se a uma magnífica provocação que consiste essencialmente em atiçar a frustração do leitor. Este não é mais para ele um homem que deve ser satisfeito, mas ao contrário, um homem a quem cabe sentir a frustração decorrente da própria engrenagem de nossas existências. Rimbaud recusa decididamente o significado e se limita a um significante que exacerba ainda mais um desejo de sentido. Os processos revolucionários de Rimbaud são postos em evidência nos poemas "Parade" e "H". 


\section{Rèsumè}

On a parlé de l' "illisibilité" des Illuminations et de la difficulté de comprendre ces textes. En fait, Arthur Rimbaud, peu soucieux du public des années 1870 dont il sait que ses poèmes débordent largement l'horizon d'attente, se livre à une magnifique provocation qui consiste essentiellement à attiser la frustration du lecteur. Le lecteur n'est plus pour lui un homme qui doit être comblé, mais au contraire un homme qui se doit de ressentir la frustration qui est le ressort même de nos existences. Rimbaud refuse résolument le signifié et se cantonne à un signifiant qui exacerbe d'autant plus un désir de sens. La démarche révolutionnaire de Rimbaud est mise en lumière dnas les poèmes "Parade" et " $\mathrm{H}$ ".

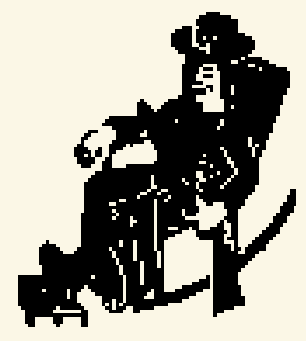

Daniel Leuwers é conferencista e professor da Universidade François-Rabelais, em Tours, na França. 